\title{
Biodegradation of Phenol in Synthetic Wastewater Using a Fixed Bed Reactor With up Flow Sludge Blanket Filtration (FUSBF)
}

\author{
Mohammad-Javad Ghannadzadeh ${ }^{1}$, Ahmad Jonidi-Jafari ${ }^{1}$, Abbas Rezaee $^{1} \&$ Reza Darvishi Cheshmeh Soltani ${ }^{2}$ \\ ${ }^{1}$ Department of Environmental Health Engineering, Faculty of Medical Sciences, Tarbiat Modares University, \\ Tehran, Iran \\ ${ }^{2}$ Department of Environmental Health Engineering, School of Health, Arak University of Medical Sciences, \\ Arak, Iran \\ Correspondence: A. Jonidi Jafari, Department of Environmental Health Engineering, School of Medical Sciences, \\ Tarbiat Modares University, Tehran, Iran. Department of Environmental Health Engineering, School of Health, \\ Iran University of Medical Sciences, Shahid Hemmat Ave, Tehran, Iran. Tel: 98-216-670-0321; Fax: \\ 98-216-670-0321. E-mail: a.jonidi@modares.ac.ir; ahmad_jonidi@yahoo.com
}

Received: February 11, 2015

Accepted: March 4, 2015 Online Published: March 26, 2015

doi:10.5539/gjhs.v7n7p120

URL: http://dx.doi.org/10.5539/gjhs.v7n7p120

\begin{abstract}
In the present study, the removal of phenol from synthetic wastewater was evaluated in a fixed bed reactor with up flow sludge blanket filtration (FUSBF) in comparison with a typical USBF system. At hydraulic retention time (HRT) of 24 hours and solid retention time (SRT) of 20 day, the effect of initial concentration of phenol $(260-1020 \mathrm{mg} / \mathrm{L})$ on phenol and chemical oxygen demand (COD) removal efficiency (\%) was investigated in both systems. The effect of the presence of fixed bed was determined throughout the operational period.

The results showed that the FUSBF system had a better ability than the typical USBF system in terms of phenol and COD removal. The average phenol and COD removal at phenol concentration of $312 \mathrm{mg} / \mathrm{L}$ was $97.52 \%$ and $92.82 \%$ for the FUSBF system and $92.80 \%$ and $82.18 \%$ for the typical USBF system, respectively. At HRT of 24 $\mathrm{h}$ and organic loading rate (OLR) of $30 \mathrm{~g} / \mathrm{m}^{-3} \cdot \mathrm{h}^{-1}$, the amount of phenol removal was $82.1 \%$. At OLR of 30 $\mathrm{g} / \mathrm{m}^{-3} \cdot \mathrm{h}^{-1}$, role of fixed bed in phenol and COD removal was $25.01 \%$ and $29.3 \%$, respectively, overall, the FUSBF system has a higher efficiency and ability than that of typical USBF and can be used for the purification of industrial wastewater containing refractory organic compounds such as phenol.
\end{abstract}

Keywords: industrial wastewater, biological degradation, phenolic compounds, fixed bed USBF

\section{Introduction}

Phenol and its compounds have many applications in chemical processes and are used as structural units in the synthesis of many organic compounds (Kirk-Othmer, 1998). They are applied in different industries such as petrochemical, oil refinery, insecticides, resin, plastic, pharmaceutical, leather, textile and paper. The concentration of phenolic compounds in the effluents of these industries is varied between one and hundreds of milligrams per liter (Pan et al., 2008; Quintanilla et al., 2008). Phenolic compounds are classified as mutagenic, teratogenic, and carcinogenic compounds (Quintanilla et al., 2008). The United States Environmental Protection Agency (USEPA) has introduced these compounds as the priority pollutants due to their inhibitory effect on biological systems (Chang et al., 1995; Rappoport, 2003; 2004, Kinsley \& Nicell, 20008). At concentrations higher than $1 \mathrm{mg} / \mathrm{L}$, phenol adversely affects the life of fishes and consequently threatens aqueous environments (Busca et al., 2008). Therefore, phenol-containing wastewater must be purified before discharge into the environment. Several physical, chemical, and biological methods were applied for phenol removal (Karthik et al., 2008); However, phenol removal by biological methods are preferred to physical and chemical methods, because they are less risky and less costly than physical and chemical techniques (Liu et al., 1996). Biodegradation of wastewater contaminants is varied and diverse. Anoxic and aerobic reactors are used for denitrification and removal of organic matters. In addition, hybrid anoxic and aerobic reactors are applied for pre-denitrification with a much more sludge return in sewages containing high amounts of organic matter (Melcer \& Nutt, 1988). Hang (1985) studied wastewater treatment of diet soft drinks factories through anoxic-aerobic method and found that in addition to stability, the COD removal rate increases in this system.. Although recent studies have introduced an advanced system of fixed film reactor (Glass et al., 2008), the technology requires the formation of 
biofilm which per three needs a period for acclimatization of microbial mass in industrial wastewater containing high concentrations of pollutants (Roeselers et al., 2008; Tziotzios et al., 2005). Many studies regarding the types of suspended growth and fixed film systems have been performed for the evaluation of phenol removal; most of them have reported higher yields with fixed film than suspended growth systems (Wang et al., 2008). Although numerous studies have used aerobic, anoxic, and anaerobic methods to remove phenol from wastewater, no report was found about the application of up flow sludge blanket filtration (USBF ) and fixed bed up flow sludge blanket filtration (FUSBF) for treating domestic and industrial wastewaters containing phenol. This approach can be used to reclaim domestic and industrial wastewaters and update the existing wastewater treatment plants (Rajakumar et al., 2011; Su et al., 2004). In this process, the wastewater enters the anoxic area and then enters from its bottom into an aeration basin; after overflow, it enters the sedimentation zone through the lower part of a clarifier. The remaining materials are returned from the bottom of the sedimentation (Su et al., 2004, Leva, 2001) Single-stage or two-stage design and operation can be carried out. All of these processes have been upgraded in a bioreactor resulting in a significant decrease in size and cost compared to other modified activated sludge systems (Punal et al., 2002, Kishida et al., 2006). The main aim of this investigation was to evaluate the capability of a single-stage FUSBF for removal of phenol from synthetic wastewater. In the following, the effect of hydraulic retention time (HRT) and organic loading rate (OLR) on phenol and COD removal was assessed.

\section{Materials and Methods}

\subsection{Start-Up}

The experiments were carried out in two well-matched, equal-size hybrid bioreactors of FUSBF and USBF in lab-scale; they were rectangular plexiglass tanks with a total volume of $20 \mathrm{~L}$ (Figure 1).

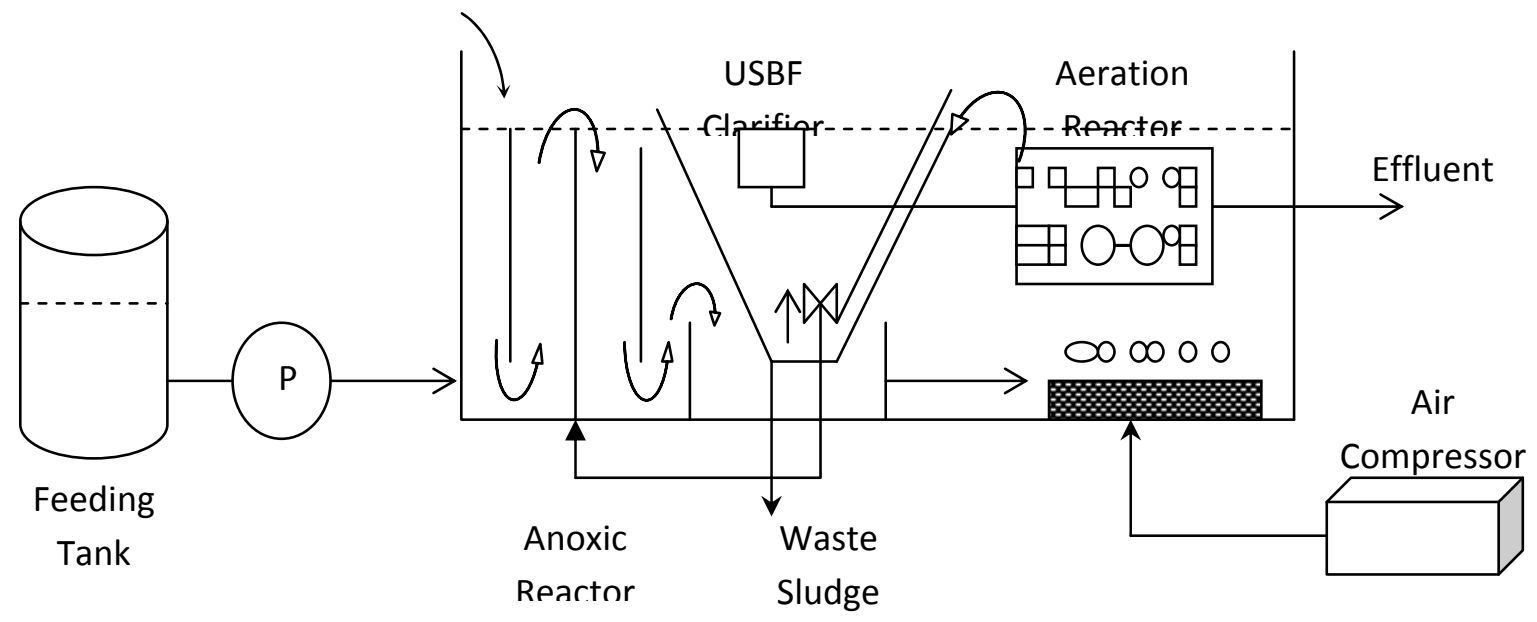

Figure 1. Schematic diagram of the lab-scale FUSBF integrated bioreactor

For FUSBF hybrid bioreactor, an aerobic fixed film was installed as an appropriate unit for further biological removal in the aerobic zone. Twenty percent of the aerobic reactor volume was filled by a media made of high density polyethylene (HDPE). Support material surface area, porosity, mean diameter and density were 400 $\mathrm{m}^{2} / \mathrm{m}^{3}, 56 \%, 14 \mathrm{~mm}$ and $97.0-92.0 \mathrm{~g} / \mathrm{cm}^{3}$, respectively. Sludge from the clarifier of FUSBF directly turned back into the anoxic area. The return activated sludge (RAS) from clarifier was measured and controlled through the amount and time of sludge return. The amount of RAS to the anoxic area was 3 times of the average inflow. The reactors were operated at room temperature $\left(25^{\circ} \mathrm{C}\right)$. The required air for aeration was mixed in the aerobic zone by an air compressor with a maximum output of $90 \mathrm{~L} / \mathrm{min}$ along with three air stone diffusers. Air flow was adjusted by hand valves so that the concentration of dissolved oxygen in the aerobic zone liquid was $4.0 \pm 0.5$ and oxidation-reduction potential (ORP) in the anoxic area was about $-30 \pm 40 \mathrm{mV}$. The $\mathrm{pH}$ of solution was maintained neutral throughout the experiments.

\subsection{Operation Method}

Synthetic wastewater, containing phenol as the carbon source, $\mathrm{NO}_{3} \mathrm{NH}_{4}$ as the nitrogen $(\mathrm{N})$ source, and $\mathrm{KH}_{2} \mathrm{PO}_{4}$ and $\mathrm{K}_{2} \mathrm{HPO}_{4}$ as the source of phosphate $(\mathrm{P})$, entered into the system throughout the operation and minor elements for biomass were added into the synthetic wastewater as follows: $\mathrm{FeCl}_{3} \cdot 6 \mathrm{H}_{2} \mathrm{O}: 1.5 \mathrm{~g} / \mathrm{L}, \mathrm{H}_{3} \mathrm{BO}_{3}: 0.15$ 
$\mathrm{g} / \mathrm{L}, \mathrm{CuSO}_{4} .5 \mathrm{H}_{2} \mathrm{O}: 0.03 \mathrm{~g} / \mathrm{L}, \mathrm{KI}: 0.03 \mathrm{~g} / \mathrm{L}, \mathrm{MnCl}_{2} \cdot 4 \mathrm{H}_{2} \mathrm{O}: 0.12 \mathrm{~g} / \mathrm{L}, \mathrm{NaMnO}_{4} \cdot 2 \mathrm{H}_{2} \mathrm{O}: 0.06 \mathrm{~g} / \mathrm{L}, \mathrm{ZnSO}_{4} \cdot \mathrm{H}_{2} \mathrm{O}: 0.12$ $\mathrm{g} / \mathrm{L}$ and $\mathrm{CoCl}_{2} \cdot 6 \mathrm{H}_{2} \mathrm{O}: 0.15 \mathrm{~g} / \mathrm{L}$ (31). The composition of wastewater was determined based on the ratio of COD/N/P: 100/5/1. The required sludge was obtained as seed from a municipal sewage treatment plant in Arak. The operational flow rate for both FUSBF and USBF bioreactors were 10-60 L/dThe operational parameters for both FUSBF and USBF bioreactors are presented in Table 1.

Table 1. Operational parameters for the lab-scale FUSBF and USBF bioreactors.

\begin{tabular}{llll}
\hline Parameter & Anoxic zone & Aerobic & Clarifier \\
\hline Volume (L) & 6 & 9 & 2 \\
HRT (h) & $2.4-14.4$ & $3.6-21.6$ & $0.8-4.8$ \\
SRT (day) & & 20 & \\
Average MLSS (mg/L) & 3290 & 3735 & 6200 \\
Average MLVSS (mg/L) & 2575 & 2865 & \\
\hline
\end{tabular}

Phenol was added increasingly and stepwise (from 0 to $260 \mathrm{mg} / \mathrm{L}$ ) to the FUSBF and USBF bioreactors during the startup. Phenol was the sole carbon source for growth of microorganisms and formation of biofilm. Synthetic wastewater was continuously prepared and supplied into both FUSBF and USBF reactors and was pumped with a flow of $20 \mathrm{~L} /$ day under the mentioned operational conditions. During the startup period, this flow level was used for $3.7 \mathrm{~h}$ and $10.8 \mathrm{~h}$ in anoxic and aerobic zones, respectively, at a HRT of 24 hours and a SRT of 20 days. Microorganisms and the biofilm were well grown under control in different concentrations of pollutants. Treatment of inflow began when the biofilm was formed and the pollutants concentration in the bioreactors outflow became constant. Under these conditions, it takes 165 and 172 days to startup the developed FUSBF and typical USBF bioreactors, respectively. Then the efficiency of the systems was evaluated with different initial concentrations of phenol and different HRT from 12 to 48 hours. The conditions for implementation of the stages were determined using a combination of parameters given in Table 1. At each stage, the experiments were performed when the bioreactors attained steady-state conditions.

\subsection{Sampling and Analysis}

Using synthetic wastewater, the systems reached to stable conditions and then were utilized. After seeding, the biofilm formed in aerobic reactor of the developed FUSBF bioreactor was visualized (in terms of morphology) using scanning electron microscopy (SEM). For this, the media was randomly sampled from various parts of the aerobic reactor at the end of the experiment in the stable stage. The withdrawn media were dried in darkness at room temperature for 12 hours before observation (Trinet et al., 1991). The biofilm concentration formed on the moving bed was determined according to the procedure used by Darvish (Soltani et al., 2013) . The samples were collected from the reactor at each operational run. Parameters measured included the levels of phenol, dissolved oxygen (DO), PH, (ORP), COD, mixed-liquor suspended solid (MLSS), and mixed-liquor volatile suspended solid MLVSS. Samples were collected and analyzed from inflow and outflow of the anoxic and aerobic reactors, as well as from clarifier. Temperature, DO, ORP, and PH were measured every day, immediately prior to sampling. To remove particles, the samples were passed from a 0.45 micron filter. MLSS, MLVSS and COD were analyzed according to standard methods for the examination of water and wastewater (APHA, 2005). Suitable probes were used to measure ORP, DO, and PH. Phenol concentration was measured using high performance liquid chromatography (HPLC); to this end, $20 \mathrm{~mL}$ of sample was injected into a 4.0-250 mm ODS C18 column (specifications). A mixture of acetonitrile/deionized water/acetic acid (50/50/1.5 $\mathrm{v} / \mathrm{v} / \mathrm{v}$ ) as the mobile phase solution was used at a flow rate of $2 \mathrm{~mL} / \mathrm{min}$. The samples were then analyzed at 270 $\mathrm{nm}$ using the UV-visible detector.

\section{Results and Discussion}

\subsection{Startup of Reactor, Acclimatization of Biomass, and Formation of Biofilm}

During acclimatization of the liquid mixture, the initial concentration of phenol was gradually increased from 60 to $260 \mathrm{mg} / \mathrm{L}$. During this period, increase in phenol degradation at each stage of phenol initial input was considered as the fulfilling of acclimatization. Then the next stage of phenol increase started. In other words, increased rate of phenol biodegradation in a range of increasing phenol concentrations confirmed that acclimatization was fulfilled, the microbial population boosted and propagated, and biomass gained the capacity 
and ability to degrade phenol under the conditions existing in both bioreactors of USBF and developed FUSBF. So biomass was prepared as a suitable seed for utilization and operation of bioreactors. The total time required for the acclimatization stage for both USBF and developed FUSBF bioreactors was 172 and 165 days, respectively. The total amount of inoculated biomass in the anoxic and aerobic reactors at startup in the USBF reactor was almost 2100 and $2480 \mathrm{mg} / \mathrm{l}$, respectively.

\subsection{Biomass Characterization of Biofilm Formation}

SEM image of the initial clean media and the biofilm containing media was used to view and characterize the surface of fixed film medium in the aerobic FUSBF reactor. As shown in Figure 2, formation of biofilm in the fixed film aerobic reactor after seeding was confirmed by the results of SEM analysis. The formation of biofilm in the FUSBF is attributed to the hydrodynamic role that results from fix bed the media in the suspension ( $G^{\prime}$ omez et al., 2003). The presence of a dense biofilm with a rough and cloven surface can be clearly seen in the SEM image (Figure 3).
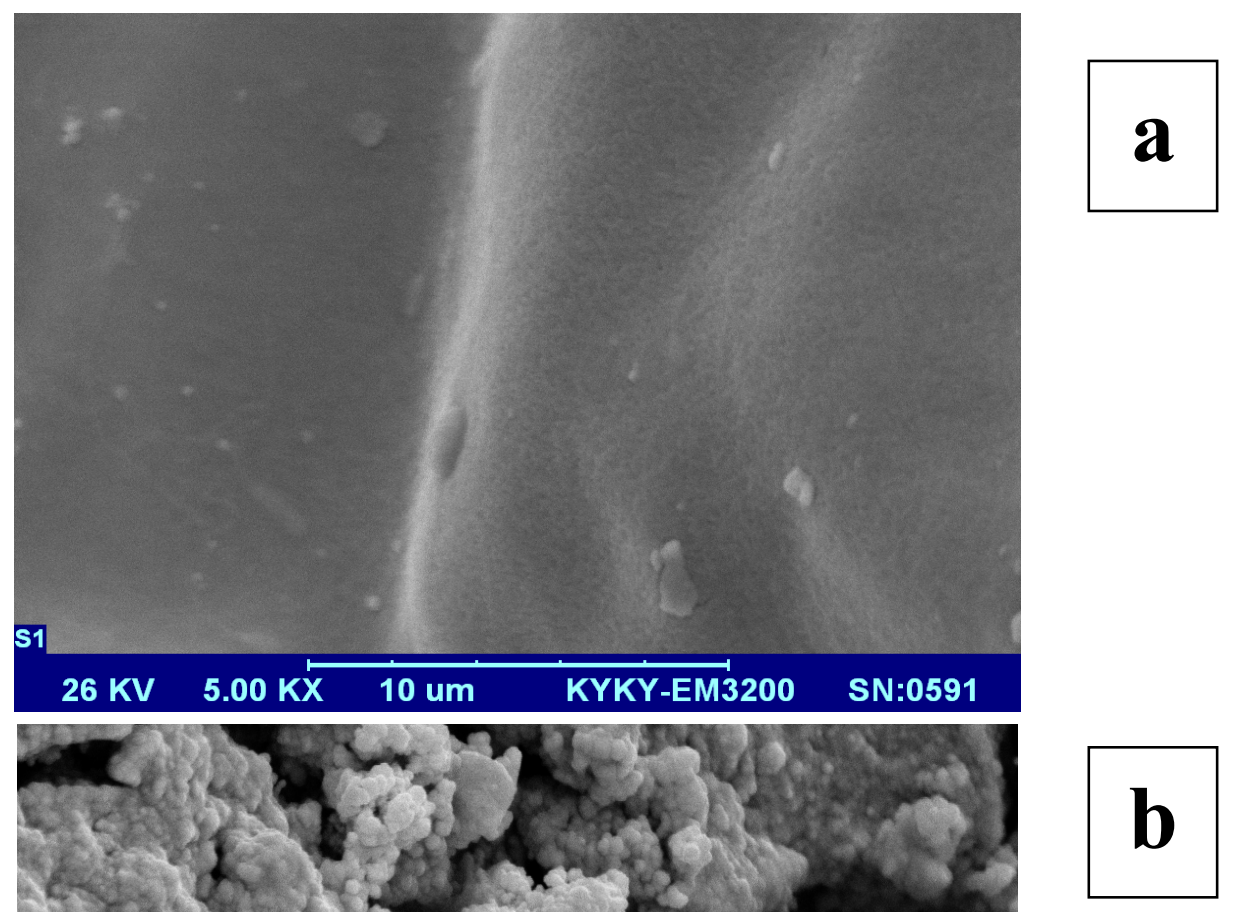

The results showed that the media used was suitable for biofilm formation or formation of biofilm and no pre-seeding was required. Figure 2(a) shows the clean and uncovered biofilm and media. As can be seen, the rough surface of the existing media is an ideal surface for formation of biofilm. Figure 2(b) shows the growth 
and development of biofilm after biofilm formation in the aeration zone of the FUSBF system. The formation of a non-uniform dense biofilm with porous properties is clearly observable. Density and morphology of biofilm in the FUSBF bioreactor is an incentive to work on the concentration of phenol and oxygen and the ability to remove pollutants (Wang et al., 2005). The morphology of biofilm formation on fixed film media can be affected by the amount of media, cross-section, and slots and grooves of the media segments in the reactor (Maran et al., 2008).

\subsection{Effect of Initial Concentration of Phenol on Its Removal Efficiency}

After a successful startup and achieving a stable stage (less than 5\% change in phenol output in a week at phenol concentration of $260 \mathrm{mg} / \mathrm{L}$ ) and confirmation of biofilm formation via SEM, the reactors were operated under conditions of HRT $=24 \mathrm{~h}$ and SRT $=20 \mathrm{~d}$ for evaluation of phenol removal at different input concentrations of 312 , 416, 520, 780, and $1020 \mathrm{mg} / \mathrm{L}$. Experiments were performed when the conditions were stable; these stable conditions were the same for all experiments and had no statistically significant difference (less than 5\%) for about 5-7 days between the results of experiments. The behavior of typical USBF and FUSBF bioreactors at HRT $=24 \mathrm{~h}$ and $\mathrm{SRT}=20 \mathrm{~d}$ was evaluated at different initial concentrations of phenol. The removal of phenol and COD was displayed as a function of initial concentration of phenol (Figure 3). The removal efficiency in both USBF and FUSBF bioreactors can be seen. As shown in Figure 3, the amount of phenol removal in both USBF and FUSBF bioreactors rises and finally reaches to 92 and 97.5, respectively, and then remained constant for the next six days.

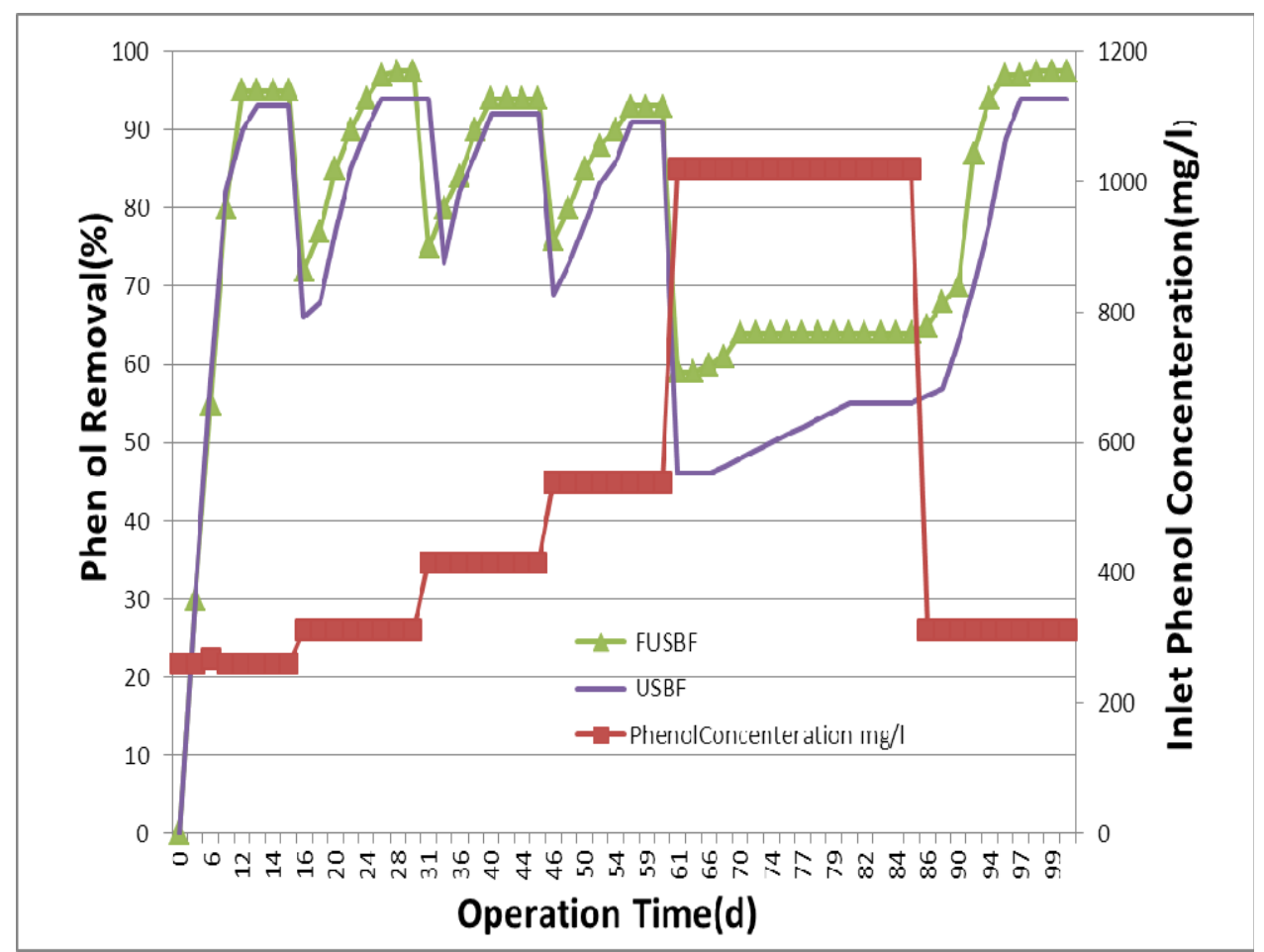

Figure 3. Phenol removal efficiency as a function of initial concentration of phenol ranging from 260 to1020 $\mathrm{mg} / \mathrm{L}$

This increase in the efficiency of daily removal of $312 \mathrm{mg} / \mathrm{L}$ phenol during the operation shows that the seed inoculated or injected into the USBF and FUSBF bioreactors was able to degrade high concentration of phenol. In a similar approach, phenol concentration was increased in a stepwise manner to $416,572,728$, and $1020 \mathrm{mg} / \mathrm{L}$ and both bioreactors were operated and evaluated until achieving steady-state condition. As seen, after a sharp increase in the concentration, for example from $416 \mathrm{mg} / \mathrm{L}$ to $572 \mathrm{mg} / \mathrm{L}$ and at any other concentration increments, the removal rate decreased at both reactors immediately the next day, although the rate of removal decline in the FUSBF reactor was less than the USBF reactor after each step of increase in concentration. For example, immediately after an increase in the concentration of phenol to $572 \mathrm{mg} / \mathrm{L}$, the removal rate of the FUSBF reactor reached to $72.3 \%$ the next day, while declined to $63.5 \%$ in the USBF reactor. However, the removal rate 
increased again in both bioreactors in the next few days of operation. In general, by increasing the concentration of phenol, the removal process had a descending trend in both bioreactors, although the highest removal rate of decline was observed at $1020 \mathrm{mg} / \mathrm{L}$ in both reactors. At this concentration, the decrease in removal efficiency was higher in the typical USBF reactor than the FUSBF reactor. In fact, although the removal rate increased again after its sudden decline at the day next to sudden increase in phenol concentration to $1020 \mathrm{mg} / \mathrm{L}$, and although both bioreactors were restored again and achieved steady state conditions, the time required to reach the steady state conditions was 20 days for FUSBF and 35 days for typical USBF bioreactor.

To confirm the capabilities of both FUSBF and typical USBF systems under the minimum inhibitory concentration of phenol and to test the revival behavior of the system caused by excessive load entered, the input concentration of phenol was reduced in a stepwise manner from $1020 \mathrm{mg} / \mathrm{L}$, to $728,572,468$, and $312 \mathrm{mg} / \mathrm{L}$. At each concentration, both bioreactors achieved the stable conditions of removal. Figure 3 shows that by returning to phenol concentration of $312 \mathrm{mg} / \mathrm{L}$, the removal efficiency in both bioreactors quickly reached to $90 \%$ of phenol removal. This high removal rate confirms that the inhibitory effect, occurred due to an increase in previous concentrations, was disappeared after decreasing the concentration (Rivas et al., 2013). Finally, phenol concentration was returned to $312 \mathrm{mg} / \mathrm{L}$ resulting in phenol degradation higher than $90 \%$ in both bioreactors. The above results clearly show that in the same operational conditions, the FUSBF bioreactor had higher resistance to the input phenol concentration than the USBF bioreactor, in particular at higher concentrations. In terms of the time, the FUSBF bioreactor restored and was able to accept higher concentrations in a shorter period. This higher resistance and ability to better revive at higher concentrations can be attributed to the protective reactions of extracellular polymeric substances which hold together the biofilm (Fang et al., 1996). In summary, the efficiency of phenol removal in steady-state conditions for input concentrations were $97.5 \%$ for FUSBF and $92.18 \%$ for typical USBF.

\subsection{Effect of Phenol Concentration on the Removal of COD}

Changes in effluent COD concentration and COD removal along with initial phenol concentration are shown in Figure 4. COD removal efficiency was higher than $90 \%$ and effluent COD concentration was less than $100 \mathrm{mg} / \mathrm{L}$ for all concentrations of less than $416 \mathrm{mg} / \mathrm{L}$, because more than $90 \%$ of phenol degraded in almost all cases of lower than $416 \mathrm{mg} / \mathrm{L}$, which had no significant inhibitory effect on COD removal. But when the phenol concentration increased to $870 \mathrm{mg} / \mathrm{L}$, the COD removal efficiency was reduced to $75 \%$. As a result, the effluent COD concentration reached to $431 \mathrm{mg} / \mathrm{L}$. This can be due to increased concentrations of phenol which may prevent the COD removal, as phenol concentrations of more than $416 \mathrm{mg} / \mathrm{L}$ declined the biodegradation of phenol (39). The COD concentration in the refined effluent in both bioreactors was higher than phenol; this can be attributed to the presence of COD arisen from intermediate compounds which degradation efficiency is generally lower than that of phenol (Sa et al., 2001).

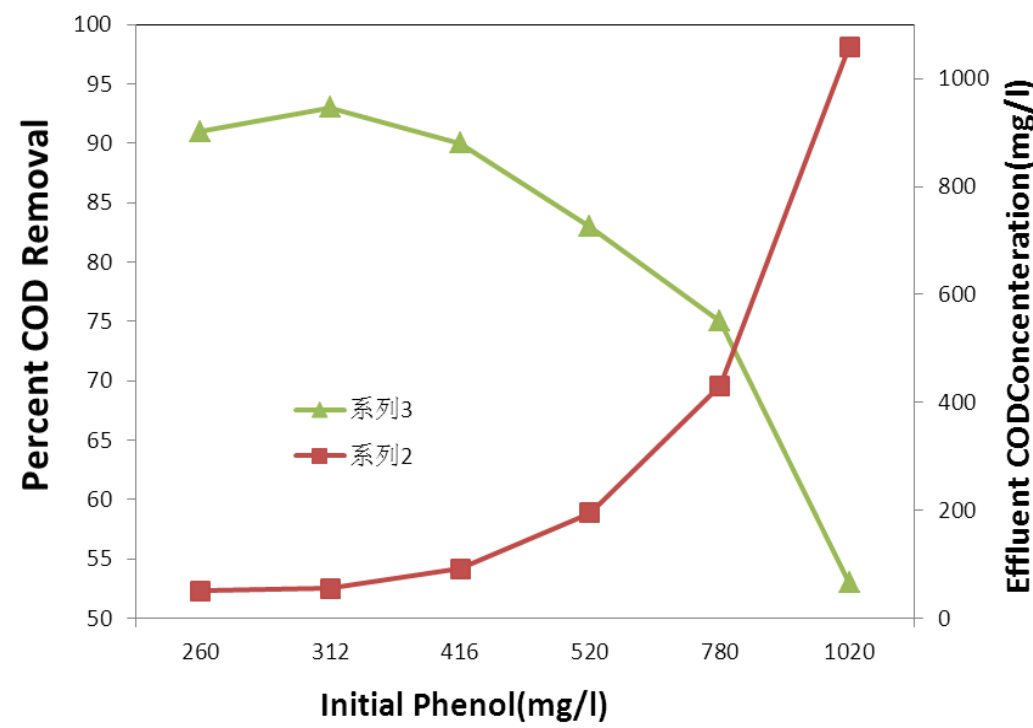

Figure 4. Variations of effluent COD concentration and COD removal efficiency as a function of initial phenol concentration 


\subsection{The Effect of Phenol Concentration on SVI}

Figure 5 depicts the changes in SVI as a result of the change in phenol concentration. For all concentrations lower than $416 \mathrm{mg} / \mathrm{L}$, SVI was almost constant at about $85 \mathrm{ml} / \mathrm{g}$. However, SVI increased at phenol concentrations higher than $416 \mathrm{mg} / \mathrm{L}$ and reached to $115 \mathrm{mg} / \mathrm{L}$ at phenol concentration of $1020 \mathrm{mg} / \mathrm{L}$. Therefore, activated sludge microorganisms probably had no important inhibitory or conflicting effect when phenol concentration increased up to $416 \mathrm{mg} / \mathrm{L}$. Overall, there were good deposition properties without any decay or inactivation. But SVI increased in concentrations higher than $416 \mathrm{mg} / \mathrm{L}$ due to inactivation and decay of microorganisms, resulting in unacceptable deposition characteristics.

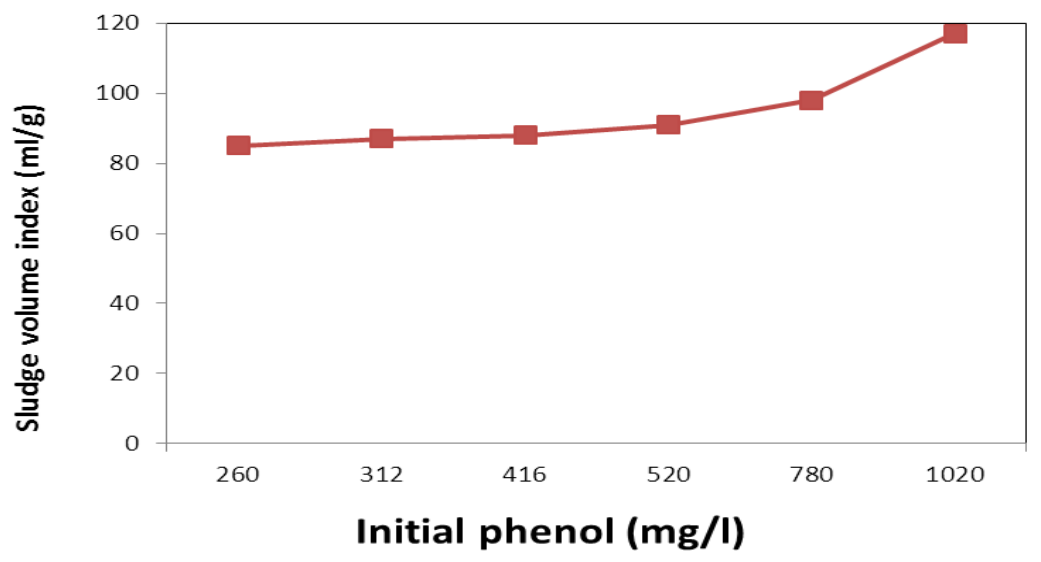

Figure 5. Variations of sludge volume index (SVI) with initial phenol concentration

\subsection{The Effect of HRT on Phenol Removal}

Biological wastewater treatment processes are cost effective only when they act highly efficient in a short time, otherwise the facilities size may not meet the requirements. Removal of phenol was evaluated at HRTs of 48,36 , 24, 12, and 8 hours in FUSBF under steady-state conditions. The phenol and COD removal under different HRTs are shown in Figure6. The reactors were operated for a period of 20 days. As results, the phenol removal (\%) for HRTs of $48,36,24,18,12$ and 8 were $97.50,97.38,97.22,89.12,82.54,67.34 \%$, respectively. The removal of COD was higher than $81 \%$ for HRTs $48,36,24$, and 18 hours, while at HRT of 12 hours, the removal efficiency was reduced to $74.84 \%$.

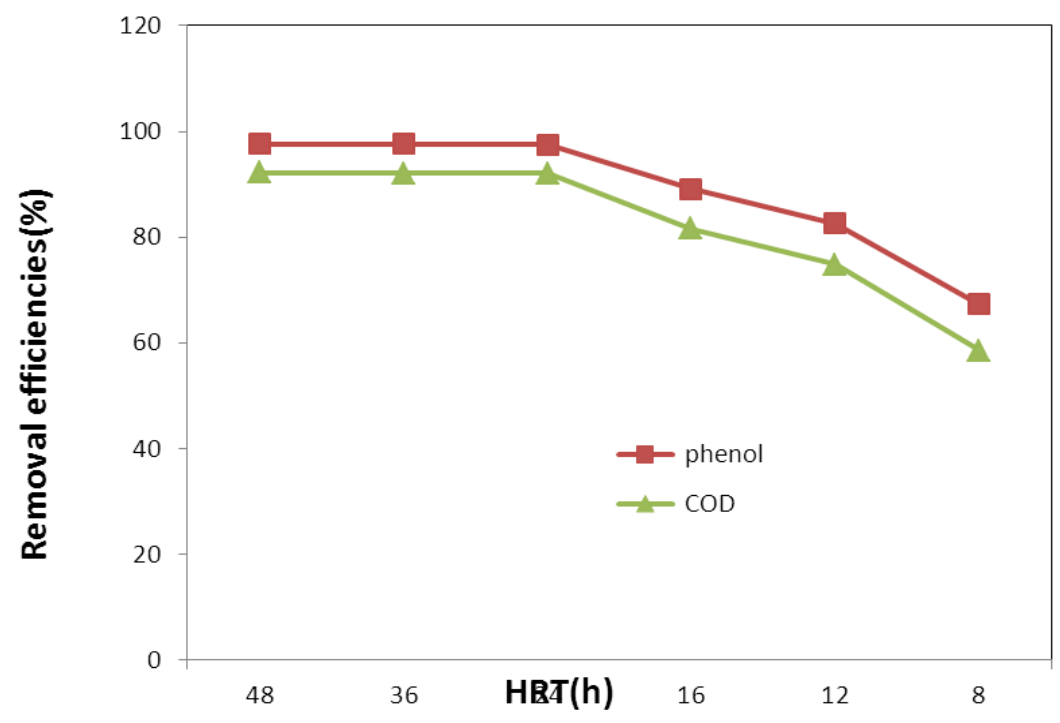

Figure 6. Variations of phenol and COD removal efficiencies under different HRTs at an initial phenol concentration of $312 \mathrm{mg} / \mathrm{L}$ 


\subsection{Role of Media in FUSBF Performance}

To better understand and explain the role of fixed bed media in operation of FUSBF system, two different loads of phenol (13 and $30 \mathrm{~g} \mathrm{phenol} / \mathrm{m}^{3} \cdot \mathrm{h}^{-1}$ ) were used and compared in both FUSBF and typical USBF. The average phenol and COD removal efficiencies are shown in Figure $7 \mathrm{a}, \mathrm{b}$, respectively.

The mean phenol and COD removal efficiency is shown in Figure7 b. As shown in Figure7 a, the role of fixed film media in the removal of phenol increases $4.9 \%$ in the load $13 \mathrm{~g}$ phenol $/ \mathrm{m}^{3} \cdot \mathrm{h}^{-1}$, while it increases $25.01 \%$ in the load $30 \mathrm{~g}$ phenol $/ \mathrm{m}^{3} \cdot \mathrm{h}^{-1}$.

This increased share following increase in the load (concentration) may be due to consumption and attraction of more phenol load by the fixed film biofilm that result in lowering of the inhibitory effect of phenol on biomass in the reactor and delaying of the inhibitory effect by the fixed film biofilm. The role of fixed film media was greater in COD removal than in phenol removal. The role of fixed film media for COD removal of phenol loads of 13 and $30 \mathrm{~g}$ phenol $/ \mathrm{m}^{3} \cdot \mathrm{h}^{-1}$ was $9.2 \%$ and $29.3 \%$, respectively, which represents an important effect of fixed film biofilm altogether on the entire process of system exploitation. This may be due to the presence and activity of fixed film biofilm in the reactor and thus an increase in the amount of mass conversion of substrate in the mixture liquid to convert biomass and form biofilm. In general, the efficiency of FUSBF for treatment of inhibitors with high concentrations such as phenol is promising
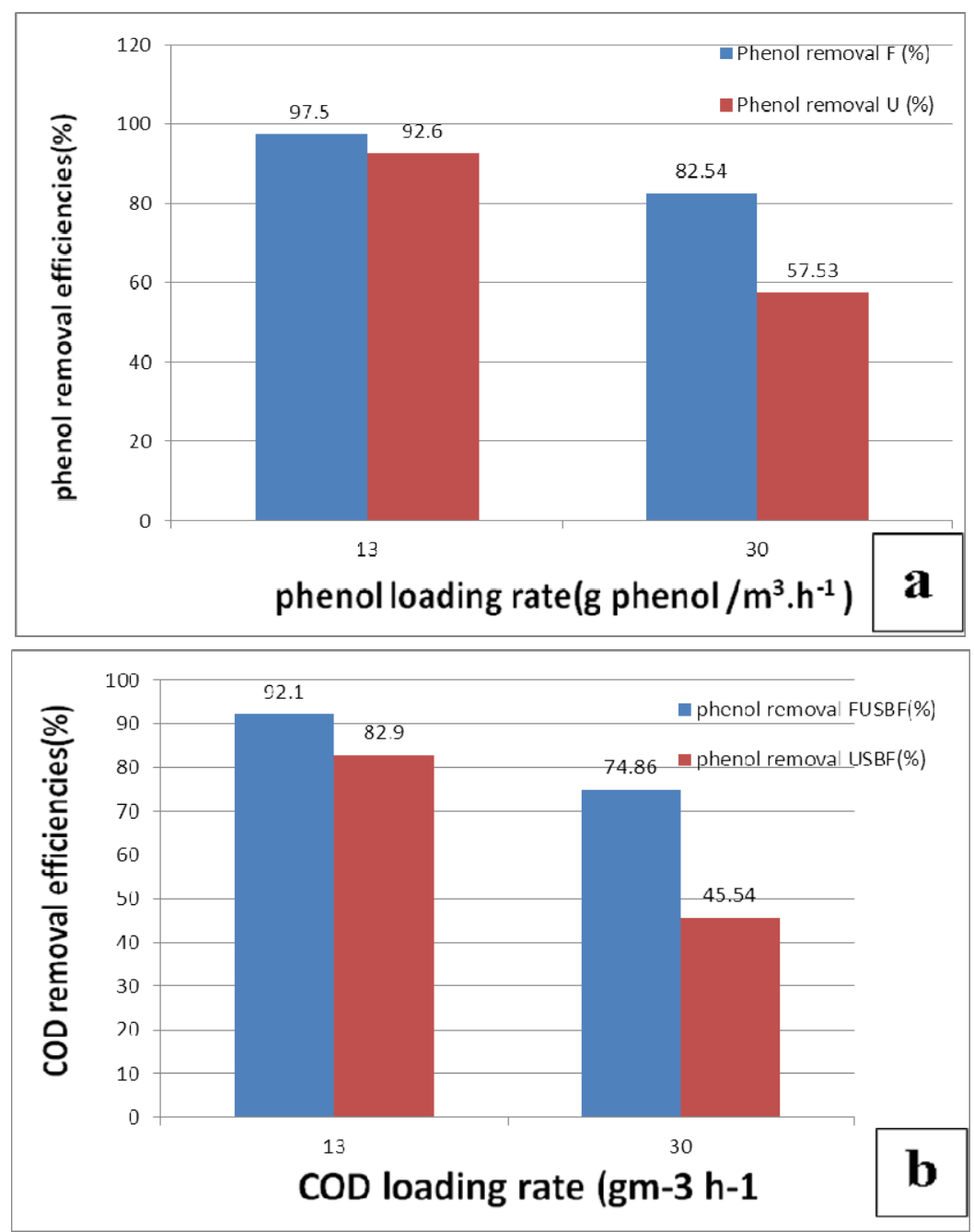

Figure 7. Average contribution of the biofilm in the efficiency of FUSBF for the removal of (a) phenol and (b) COD at different organic loading rates 


\section{Conclusion}

In the present work, an FUSBF process was developed and studied removal. The fix film USBF intergraded bioreactor at the optimum condition can be an effective technology for phenol removal from synthetic wastewater.

In this type of system microbial fixation and biofilm formation the support surface are two of the most important factors. Since they affect the levels of elimination of every pollution concentration in a synthetic wastewater. The results reveal that the FUSBF provides inproved phenol and COD removal efficiencies better than the conventional USBF, when it is operated as a single reactor with $20 \%$ media volume. The inhibition concentration of phenol in FUSBF and USBF are $1020 \mathrm{mg} / \mathrm{l}$. The optimum HRT for the FUSBF is $24 \mathrm{~h}$, at which the removal efficiencies of phenol and COD are greater than $90 \%$ The critical phenol leading rate for the FUSBF is $30 \mathrm{~g}$ phenol/m-3 .h. Which gives a phenol removal efficiency of 82.54(\%) The reactor FUSBF demonstrates a high capacity for phenol removal compared to the USBF reactor. Accordingly the FUSBF is an efficient reactor phenol compound removal.

\section{Acknowledgement}

The authors would like to thank the Tarbiat Modares University, Iran for financial and technical supports.

\section{References}

Autenrieth, R. L., Bonner, J. S., Akgerman, A., Okaygun, \& MMcCreary, E. M. (1991). Biodegradation of phenolic wastes. J. Hazard. Mater. 28, 29-53. http://dx.doi.org/10.1016/0304-3894 (91)87004-L

Boltz, J. P., Johnson, B. R., Daigger, G. T., \& Sandino, J. (2009). Modeling integrated fixed-film activated sludge and moving-bed biofilm reactor systems I: mathematical treatment and model development. Water Environment Research, 81(6), 555-575. http://dx.doi.org/10.2175/106143008X357066

Busca, G., Berardinelli, S., Resini, C., \& Arrighi, L. (2008). Technologies for the removal of phenol from fluid streams: a short review of recent developments. Journal of Hazardous Materials, 160(2), 265-288. http://dx.doi.org/10.1016/j.jhazmat.2008.03.045

Carvalho, G., Lemos, P. C., Oehmen, A., \& Reis, M. A. (2007). Denitrifying phosphorus removal: linking the process performance with the microbial community structure. Water Research, 41(19), 4383-4396.

Chang, Y. J., Nishio, N., \& Nagai, S. (1995). Characteristics of granular methanogenic sludge grown on phenol synthetic medium and methanogenic fermentation of phenolic wastewater in a UASB reactor. $J$. Fermentation Bioeng, 79, 4348-4353.

Dutch Foundationfor Applied Water Research. (2007). USBF Process. Retrieved from http://www.stowaselectedtechnologies.nl/Sheets/Sheets/USBF.Process.html

Eckenfelder Jr, W. W. (2000). Industrial Water Pollution Control (3rd ed.). Boston, MA: McGraw-Hill Inc.

Fang, H. H., Chen, T., Li, Y. Y., \& Chui, H. K. (1996). Degradation of phenol in wastewater in an upflow anaerobic sludge blanket reactor. Water Research, 30(6), 1353-1360. http://dx.doi.org/10.1016/0043-1354 (95)00309-6

Glass, C., \& Silverstein, J. (1999). Denitrification of high-nitrate, high-salinity wastewater. Water Research, 33(1), 223-229. http://dx.doi.org/10.1016/S0043-1354 (98)00177-8

Gomez, M. A., Galvez, J. M., Hontoria, E., \& González-López, J. (2003). Influence of ethanol concentration on biofilm bacterial composition from a denitrifying submerged filter used for contaminated groundwater. Journal of bioscience and bioengineering, 95(3), 245-251. http://dx.doi.org/10.1016/S1389-1723 (03)80024-5

Karthik, M., Dafale, N., Pathe, P., \& Nandy, T. (2008). Biodegradability enhancement of purified terephthalic acid wastewater by coagulation-flocculation process as pretreatment. Journal of hazardous materials, 154(1), 721-730. http://dx.doi.org/10.1016/j.jhazmat.2007.10.085

Kim, H. S., Gellner, J. W., Boltz, J. P., Freudenberg, R. G., Gunsch, C. K., \& Schuler, A. J. (2010). Effects of integrated fixed film activated sludge media on activated sludge settling in biological nutrient removal systems. Water research, 44(5), 1553-1561. http://dx.doi.org/10.1016/j.watres.2009.11.001

Kinsley, C., \& Nicell, J. A. (2000). Treatment of aqueous phenol with soybean peroxidase in the presence of polyethylene glycol. Bioresource Technology, 73(2), 139-146. http://dx.doi.org/10.1016/S0960-8524 (99)00151-0 
Kirk-Othmer. (1998). Encyclopedia of Chemical Technology (3rd ed.). New York: Wiley Interscience. ATSDR.Toxicological profile for phenol. U.S Department of Health and Human Services. Agency for Toxic Substances and Disease Registry, Division of Toxicology. Toxicology Information Branch. Atanta. Georgia., 1998.

Kishida, N., Kim, J., Tsuneda, S., \& Sudo, R. (2006). Anaerobic/oxic/anoxic granular sludge process as an effective nutrient removal process utilizing denitrifying polyphosphate-accumulating organisms. Water Research, 40(12), 2303-2310.

Lin, Y. H., Wu, C. L., Hsu, C. H., \& Li, H. L. (2009). Biodegradation of phenol with chromium (VI) reduction in an anaerobic fixed-biofilm process - kinetic model and reactor performance. Journal of hazardous materials, 172(2), 1394-1401. http://dx.doi.org/10.1016/j.jhazmat.2009.08.005

Liu, J., Wang, B., Li, W., Jin, C., Cao, X., \& Wang, L. (1996). Removal of nitrogen from coal gasification and coke plant wastewaters in A/O submerged biofilm-activated sludge (SBF-AS) hybrid system. Water Science and technology, 34(10), 17-24. http://dx.doi.org/10.1016/S0273-1223 (96)00692-0

Maranon, E., Vazquez, I., Rodriguez, J., Castrillon, L., Fernandez, Y., \& Lopez, H. (2008). Treatment of coke wastewater in a sequential batch reactor (SBR) at pilot plant scale. Bioresource technology, 99(10), 4192-4198. http://dx.doi.org/10.1016/j.biortech.2007.08.081

Melcer, H., \& Nutt, S. G. (1988). Nitrogen control of complex industrial wastewaters. Journal of Environmental Engineering, 114(1), 166-178. http://dx.doi.org/10.1061/ (ASCE) 0733-9372(1988)114:1(166)

Metcahf, E. (2003). Wastewater engineering: treatment and reuse. McGrawHill, New York, 2003.

Mosquera-Corral, A., Sanchez, M., Campos, J. L., Mendez, R., \& Lema, J. M. (2001). Simultaneous methanogenesis and denitrification of pretreated effluents from a fish canning industry. Water research, 35(2), 411-418. http://dx.doi.org/10.1016/S0043-1354 (00)00288-8

Pan, G., \& Kurumada, K. I. (2008). Hybrid gel reinforced with coating layer for removal of phenol from aqueous solution. ChemEng. J., 138, 194-199. http://dx.doi.org/10.1016/j.cej.2007.06.025

Punal, A., Roca, E., \& Lema, J. M. (2002). An expert system for monitoring and diagnosis of anaerobic wastewater treatment plants. Water Research, 36(10), 2656-2666. http://dx.doi.org/10.1016/S0043-1354 (01)00484-5

Quintanilla-Guerrero, F., Duarte-Va'zquez, M. A., Garcı'a Almendarez, B. E., Tinoco, R., Vazquez-Duhalt, R., \& Regalado, C. (2008). Polyethylene glycol improves phenol removal by immobilized turnip peroxidase. Bioresour. Technol., 99, 8605-8611. http://dx.doi.org/10.1016/j.biortech.2008.04.031

Rajakumar, R., Meenambal, T., Banu, J. R., \& Yeom, I. T. (2011). Treatment of poultry slaughterhouse wastewater in upflow anaerobic filter under low upflow velocity. International Journal of Environmental Science \& Technology, 8(1), 149-158.

Rappoport, Z. (2003). The Chemistry of Phenols. John Wiley\& Sons, Ltd. http://dx.doi.org/10.1002/0470857277

Reboleiro-Rivas, P., Martín-Pascual, J., Juárez-Jiménez, B., Poyatos, J. M., Hontoria, E., Rodelas, B., \& González-López, J. (2013). Enzymatic activities in a moving bed membrane bioreactor for real urban wastewater treatment: effect of operational conditions. Ecological Engineering, 61, 23-33.

Roeselers, G., Van Loosdrecht, M. C. M., \& Muyzer, G. (2008). Phototrophic biofilms and their potential applications. Journal of applied phycology, 20(3), 227-235. http://dx.doi.org/10.1007/s10811-007-9223-2

Sá, C. S. A., \& Boaventura, R. A. R. (2001). Biodegradation of phenol by Pseudomonas putida DSM 548 in a trickling bed reactor. Biochemical Engineering Journal, 9(3), 211-219. http://dx.doi.org/10.1016/S1369-703X (01)00149-8

Soltani, R., Rezaee, A., Godini, H., Khataee, A. R., \& Jorfi, S. (2013). Organic matter removal under high loads in a fixed-bed sequencing batch reactor with peach pit as carrier. Environmental Progress \& Sustainable Energy, 32(3), 681-687.

Sriwiriyarat, T., Ungkurarate, W., Fongsatitkul, P., \& Chinwetkitvanich, S. (2008). Effects of dissolved oxygen on biological nitrogen removal in integrated fixed film activated sludge (IFAS) wastewater treatment process. Journal of Environmental Science and Health Part A, 43(5), 518-527. http://dx.doi.org/10.1080/10934520701796481

Su, S. T., Wu, R. M., \& Lee, D. J. (2004). Blanket dynamics in upflow suspended bed. Water research, 38(1), 
89-96.

Trinet, F., Heim, R., Amar, D., \& Chang, H. T. (1991). Study of biofilm and fluidization of bioparticles in a three-phase liquid-fluidized-bed reactor. Water Science \& Technology, 23(7-9), 1347-1354.

Tziotzios, G., Teliou, M., Kaltsouni, V., Lyberatos, G., \& Vayenas, D. V. (2005). Biological phenol removal using suspended growth and packed bed reactors. Biochemical engineering journal, 26(1), 65-71. http://dx.doi.org/10.1016/j.bej.2005.06.006

Wang, L. K., Shammas, N. K., \& Hung, Y. T. (2008). Advanced biological treatment processes (pp. 365-408). New York, USA: Humana Pr Inc.

Wang, R. C., Wen, X. H., \& Qian, Y. (2005). Influence of carrier concentration on the performance and microbial characteristics of a suspended carrier biofilm reactor. Process Biochemistry, 40(9), 2992-3001. http://dx.doi.org/10.1016/j.procbio.2005.02.024

Yang, K., He, J., Dougherty, M., Yang, X., \& Li, L. (2009). Municipal wastewater treatment through an aerobic biofilm SBR integrated with a submerged filtration bed. http://dx.doi.org/10.2166/wst.2009.041

\section{Copyrights}

Copyright for this article is retained by the author(s), with first publication rights granted to the journal.

This is an open-access article distributed under the terms and conditions of the Creative Commons Attribution license (http://creativecommons.org/licenses/by/3.0/). 